\section{Organization in free recall with verbal and pictorial modes of input and output}

\author{
IRA FISCHLER* and C. RICHARD PUFF
}

Franklin and Marshall College, Lancaster, Pa. 17604

A list of 16 concrete nouns was presented as words or as simple drawings. The Ss either wrote the verbal labels for recalled items or drew simple pictures of them. The results revealed no effects of mode of input or output upon ease of recall. However, more intertrial organization was observed with word-presentation groups, and in later trials, with word recall.

Free recall memory for pictures $(P)$ or objects has been frequently found to be superior to that for the corresponding word (W) stimuli (e.g., Ducharme \& Fraisse, 1965; Sampson, 1970). The attempt to understand this superiority has recently led to the examination of subjective, or intertrial, organization in the recall of $\mathrm{P}$ and $\mathrm{W}$ stimuli. Paivio, Rogers, \& Smythe (1968) found $P$ recall greater than $W$ on the first two of four trials, but there were no differences in organization. On the other hand, Paivio \& Csapo (1969) found a significant effect on organization attributable to the use of $P$, abstract $W$, and concrete $W$ stimuli, though a specific comparison between the $\mathrm{P}$ and the corresponding concrete $W$ stimuli was not reported. The purpose of the present study was to explore further the possible role of intertrial organization in $P$ and $W$ recall. SUBJECTS

The Ss were 60 male undergraduate students at Franklin and Marshall College. They were randomly assigned conditions on order of appearance at the laboratory.

\section{MATERIALS}

The nature of the design required a carefully controlled set of stimulus materials. When presented as pictures, the items had to be quickly and consistently labeled. In addition, the motor time required for drawing a picture of an item and writing the word for that item had to be as equal as possible. Obvious interitem associative relationships were minimized, and items beginning with the same phoneme were avoided. An initial pool of 35 items was presented in $P$ and $W$ form to 12 pilot $S$ sho labeled the $P$ items and drew the $W$ items over a series of four trials. Sixteen items were finally selected. Even for these items, the mean drawing time did not exactly equal the mean writing time until the third

* Now at Stanford University, Stanford Calif. 94305. Requests for reprints should be addressed to the second author. pilot-test trial. The chosen items were: arrow, baseball, cane, door, envelope, flower, glass, heart, keyhole, ladder, match, pin, scissors, tie, umbrella, and wrench.

The $P$ stimuli were handdrawn in black on white, and the $W$ stimuli were typed. The items were reproduced on $2 \times 2$ in. slides which were presented by an automatic projector. Five randomized orders of presentation of the 16 items were prepared, and the order of these was in turn randomized in blocks of five for each S. A data sheet comprising $16 \quad 1 \times 2$ in. rectangles was used in all conditions, and a cardboard mask was used to cover responses.

\section{PROCEDURE}

Each $\mathbf{S}$ was tested individually. The instructions indicated whether $\mathrm{S}$ would be presented with $\mathrm{P}$ or W stimuli and whether $S$ had to make simple drawings $(P)$ of the items he had seen or to give written (W) responses. This gave four combinations of conditions: P-P, P-W, W-P, and W-W. In the conditions where $S$ had to draw the items, exactness and artistic merit were deemphasized. Otherwise, all Ss were told that they could recall the items in any order. The stimuli were presented at a rate of one every $2.5 \mathrm{sec}$, and $2 \mathrm{~min}$ were allowed for recall. Trials continued until $S$ had (1) completed a minimum of 12 trials, and (2) reached a criterion of two consecutive perfect recalls.

RESULTS

Ten of the $60 \mathrm{Ss}$ failed to reach the criterion of two consecutive perfect trials and were terminated after the 24th trial. The number of these $\mathrm{Ss}$ in each group was as follows: P-P(1), $\mathrm{W}-\mathrm{P}(2), \mathrm{P}-\mathrm{W}(5)$, and W-W(2). Analyses with and without these Ss were not different so only those based upon all Ss are reported. The 24 th trial was arbitrarily defined as the criterion for these Ss.

The number of correct responses is shown in Fig. 1. The analysis (two between-Ss variables and one within-Ss variable) of these data indicated that neither mode of presentation, $F(1,56)=.92$, nor mode of recall, $\mathrm{F}(1,56)=.49$, had any significant overall effect. And, while the effect of $\mathrm{trials} \quad \mathrm{s}$ as $\mathrm{significant,}$ $F(11,616)=115.00, p<.001$, none of the first-order interactions reached the .05 level. The three-way interaction,

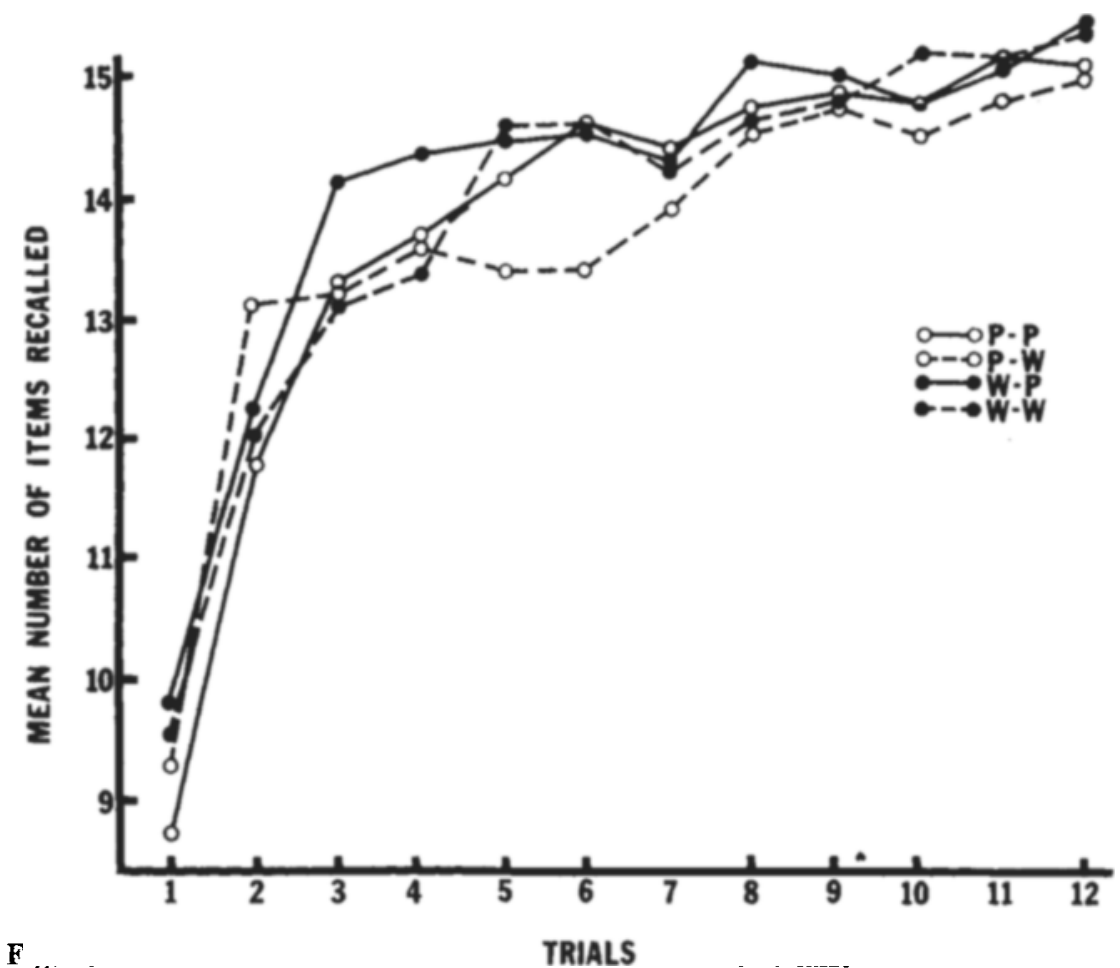

Psychon. Sci., 1971, Vol. 22 (2) 


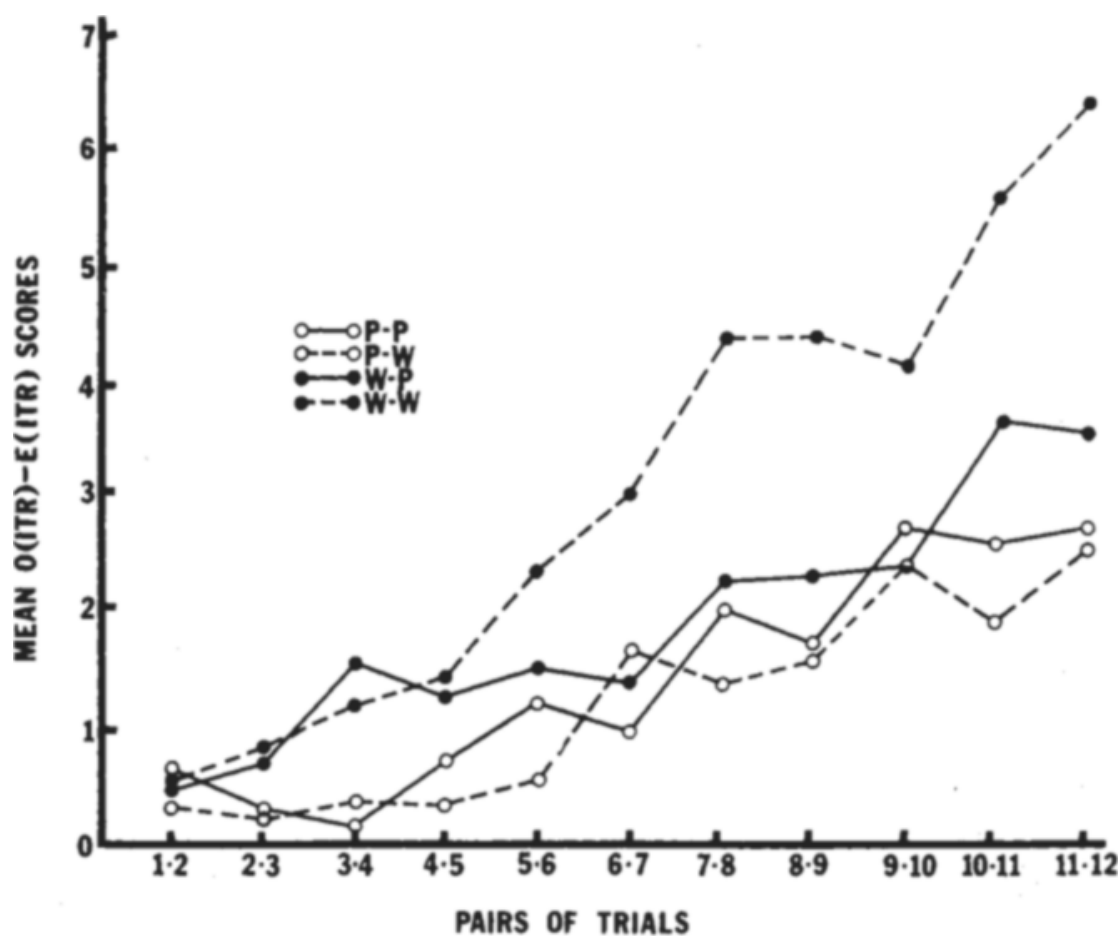

Fig. 2. Mean intertrial organization scores as a function of pairs of trials.

however, was significant, $F(11,616)=2.35, p<.05$. Inspection suggests that this probably reflects a relative plateau, or dip, in P-W performance on Trials 4-6, though this effect would not seem to warrant much emphasis at this time.

The amount of intertrial, or subjective, organization was also examined. A unit of observed intertrial repetition, O(ITR), was scored each time an item was followed in recall by the same additional item on two consecutive trials. The amount of ITR expected on the basis of chance, $\mathrm{E}(\mathrm{ITR})$, was calculated according to the formula provided by Bousfield \& Bousfield (1966). The E(ITR) values were then subtracted from the O(ITR) values, and subsequent analyses were based upon O-E(ITR) difference scores. The mean amount of O-E(ITR) is shown in Fig. 2. The analysis of these data across all 11 trial pairs indicated that the $W$ presentation groups had more organization overall than did the $P$ presentation groups, $\mathrm{F}(1,56)=7.81, \quad \mathrm{p}<.01$, and the interaction supported the observation that the difference between presentation conditions grew as a function of trials, $F(10,560)=2.28$, $\mathrm{p}<.01$. The interaction between mode of recall and trials was also significant, $F(10,560)=1.97, p<.05$. However, the three-way interaction failed to reach significance, $F(10,560)=1.74, p>.05$. Thus, there was only indirect support in this analysis for the strong impression given by the figure that the ITR for differences in trials to criterion were found.

\section{DISCUSSION}

Briefly, the results indicate that the manipulation of neither the mode of input nor the mode of output had any detectable effect on amount of recall, and while $\mathrm{Ss}$ who saw $\mathrm{P}$ stimuli produced less total organization, they showed more agreement in ordering than did Ss given W stimuli.

The recall results of most previous studies have been consistent with the dual-encoding hypothesis (e.g., see Sampson, 1970). This hypothesis suggests that $\mathrm{P}$ stimuli are encoded both visually and verbally, while $W$ stimuli are encoded only verbally, and that the double encoding facilitates memory for the $\mathrm{P}$ stimuli. The present recall data are not in agreement with previous results or with the hypothesis. This is unexplained at present and is especially surprising since Sampson (1970) recently found recall in a $\mathrm{P}-\mathrm{P}$ condition better than in $\mathrm{W}-\mathrm{W}$, and some of the stimulus items in the two studies were identical. However, Paivio, Rogers, \& Smythe (1968) found that the superiority of $P$ stimuli washed out after two trials, so a rather weak effect is not unheard of.

Seemingly, the dual-encoding hypothesis also leads to the

expectation of greater subjective ordering of recall with $P$ stimuli. These kinds of ordering are presumably based upon mediating activities, and the double encoding of $P$ stimuli should increase the probability of discovering effective mediators. The results of the study by Paivio \& Csapo (1969) may support this notion, but those by Paivio, Rogers, \& Smythe (1968) do not, and the present intertrial organization data show exactly the opposite-greater organization with $W$ stimuli. At the same time, it was found that Ss who saw $P$ stimuli had greater agreement in the way they ordered their responses. Unfortunately, it is impossible to tell which of the two ordering measures might afford a better reflection of the actual nature of the mediating processes.

Finally, the results obtained here indicate greater organization of recall during later trials by the W-W group. This cannot simply reflect input-output mode compatibility, or similar results would have been found in the P-P group. The effect must, therefore, be due to the verbal nature of both the input and output. This may be a suggestion that the important mediating processes in ITR are verbal.

\section{REFERENCES}

BOUSFIELD, A. K., \& BOUSFIELD, W. A. The measurement of clustering and of sequential constancies in repeated free 
recall. Psscholugical Reports, 1966. 19. $9.35-942$.

BOUSFIELD, W. A.. PLFF, C. R., COll AN. T. il The development of constancies in sequential organization during repeated fret recall. Joumal of Verbal Learning \& Verbal Behavior. 1964 . 3. 489.495 .

DLCHARMF, R.. \& FRAISSE. P. Etude genetique de la memorisation de mots et d'images. Canadian Journal of Psychology, 1965, 19, 253-261.

HOFSTEE. W. B. Estimating concordance in a set of rank orders. Psychological
Reports. $1968,23,1279-1283$

PAIVIO A \& CSAPO K Concrete inage and verbal nemory codes. Journal of Fiperimental Psychology, 1969. 80. $279-285$.

PAIVIO. A. ROGERS. T. B., \& SMYTHE. P. C. Why are pictures easier to recall than words? Psychonomic Science, 1968 $11,137-138$

SAMPSON,J. R. Free recall of verbal and non-verbal stimuli. Quarterly Joumal of Experimental Psychology. 1970, 22. 215-221
1969). The pres(nt experiment was an attempt to extend the findings of the Paivio and Rowe study by examining picture discrimination performance in the VD paradigm. Since pictures presumably arouse images more readily than do high-I words, this addition represents an operational extension of the imagery dimension and generates the prediction that pairs of pictures should be even easier to discriminate than high-I word pairs. The superiority of pictorial over verbal material has been demonstrated in paired-associate learning (Paivio \& Yarmey, 1966; Wicker, 1970), free recall (Paivio, Rogers, \& Smythe, 1968 ; Sampson, 1970), and recognition memory (Shepard, 1967), but the one available study on picture-word comparisons in VD learning (Goulet \& Sterns, in press) showed picture pairs to be inferior to their verbal labels. However, that experiment was conducted with groups of fourth-grade children, and it is still possible that the above predictions hold with adult Ss.

\section{METHOD}

The Ss were 60 young adults (33 males), aged 14-20, with a median age between 15 and 16 years, most of whom were high school students. All were obtained from a London youth recreation center and were paid $\$ 1.00$ for participating in the study.

Three 14-pair VD lists were used. Lists $C$ and $A$ comprised high-I concrete nouns and low-I abstract nouns, respectively, selected from the Paivio, Yuille, \& Madigan (1968) norms. The mean I ratings were 6.54 for List C and 3.02 for List A. All items had Thorndike-Lorge frequency values greater than $45 /$ million. The meaningfulness $(m)$ of the words covaried with $I$, but this confounding is unimportant since $m$ has been found to have no effect on VD learning (Paivio \& Rowe, 1970). List P comprised pairs of pictures (line drawings) whose labels made up the items of List C. The pictures were selected from a pool for which normative data on labeling consistency, rated familiarity, and labeling latency were available. All were labeled consistently by at least $83 \%$ of the normative sample of 30 university students, the mean value being 92 . Familiarity and labeling latency were uncontrolled.

The pairs of items were photographed frame by frame on $16-\mathrm{mm}$ black-and-white film, with the words typed in capital IBM Discovery type and presented by means of an LW Motion Analyser. Testing was carried out in groups of 2-6, a total of $20 \mathrm{Ss}$ (11 males) being assigned to each of the three list conditions. Conventional $V D$ instructions for a study-test 